\title{
Comprehensive Study on Elastic Moduli Prediction and Correlation of Glass and Glass Ceramic Derived from Waste Rice Husk
}

\author{
Chee Sun Lee, ${ }^{1}$ Khamirul Amin Matori, ${ }^{1,2}$ Sidek Hj. Ab Aziz, ${ }^{1}$ Halimah Mohamed Kamari, ${ }^{1}$ \\ Ismayadi Ismail, ${ }^{2}$ and Mohd Hafiz Mohd Zaid ${ }^{1,2}$ \\ ${ }^{1}$ Department of Physics, Faculty of Science, Universiti Putra Malaysia (UPM), 43400 Serdang, Selangor, Malaysia \\ ${ }^{2}$ Materials Synthesis and Characterization Laboratory, Institute of Advanced Technology, Universiti Putra Malaysia (UPM), \\ 43400 Serdang, Selangor, Malaysia
}

Correspondence should be addressed to Mohd Hafiz Mohd Zaid; mhmzaid@gmail.com

Received 2 March 2017; Accepted 24 July 2017; Published 24 August 2017

Academic Editor: Gianluca Cicala

Copyright (C) 2017 Chee Sun Lee et al. This is an open access article distributed under the Creative Commons Attribution License, which permits unrestricted use, distribution, and reproduction in any medium, provided the original work is properly cited.

Zinc silicate $\left(\mathrm{ZnO}-\mathrm{SiO}_{2}\right)$ systems were fabricated using zinc oxide $(\mathrm{ZnO})$ and white rice husk ash (WRHA) with compositions of $(\mathrm{ZnO})_{x}(\mathrm{WRHA})_{1-x}(x=0.55,0.60,0.65$, and $0.70 \mathrm{wt} . \%)$ was symbolized by S1, S2, S3, and S4, respectively. The $\mathrm{ZnO}_{-} \mathrm{SiO}_{2}$ samples were fabricated by applying the melt-quench method and the physical and elastic properties of the samples were investigated. Physical properties used in this study are density and molar volume while the theoretical elastic moduli of the samples produced were obtained using direct calculation of theoretical model compared with the experimental elastic moduli obtained by acquiring ultrasonic velocities using ultrasonic pulse-echo technique. Values of experimental elastic moduli including longitudinal modulus $(L)$, shear modulus $(S)$, Young's modulus $(E)$, bulk modulus $(K)$, and Poisson's ratio $(\sigma)$ were compared with theoretical model calculated using Rocherulle's model. All the configurations of the elastic moduli obtained experimentally match very well with the configuration from Rocherulle's model but Poisson's ratio obtained experimentally differs from the values of Poisson's ratio obtained through Rocherulle's model.

\section{Introduction}

Rice is the main source of carbohydrates and consumption for the populations in Asia and the main by-product is the waste rice husk $(\mathrm{RH})$ which is produced in a vast production of paddy field in Malaysia and also throughout the globe. Rice cultivation in Malaysia has resulted in 400,000 metric tonnes of RH annually as it has been considered valueless and the main problem arises once it comes to the problem of getting rid of it [1]. RH is obtained as a worthless by-product as it cannot fetch a good price in the open market and most of the RH milling factories are massively influenced by this problem and disposing $\mathrm{RH}$ ethically will become unprofitable for them $[2,3]$. RH produced is generally discarded or burned and this has caused a serious threat to our mother earth and by developing new ways to reuse $\mathrm{RH}$, it can be a useful by-product such as substitution for conventional silica in the glass industry $[4,5]$. Next, substitution silica such as white rice husk ash (WRHA) can be derived from RH by a complete combustion [6]. RH serves as good substituents for conventional silica as it possesses high concentration of silica after complete combustion of $1000^{\circ} \mathrm{C}$ from WRHA and it has relatively lower cost compared to its conventional silica counterpart $[7,8]$. RH glass system which is derived can be doped into lithium silicate glass system and it mimics the thermal behavior and crystalline phases of the glass and glass ceramic lithium silicate systems and it also increases the fracture toughness of both systems by $100 \%$ thus implying that $\mathrm{RH}$ will act as an adequate replacement for conventional silica [9]. RH glass ceramic can be used to derive nepheline-forsterite glass ceramic where its main source of silica is from WRHA [10].

Zinc silicate $\left(\mathrm{ZnO}-\mathrm{SiO}_{2}\right)$ glass is an amorphous glass with high concentration of $\mathrm{ZnO}$ in its major composition and it grabs much attention from researches as it possesses various 
applicable uses in the range of glass ceramics and technical glasses [11]. Researchers can do a lot more to understand the applications of $\mathrm{ZnO}-\mathrm{SiO}_{2}$ glass and by variating $\mathrm{SiO}_{2}$ and $\mathrm{ZnO}$ compositions, endless possibilities can be achieved. $\mathrm{ZnO}$ is one of the major compositions in the samples produced and incorporating it in the glass and glass ceramic system makes $\mathrm{ZnO}-\mathrm{SiO}_{2}$ system a remarkable one. $\mathrm{ZnO}$ based glass is one of the most interesting network modifiers in the list of all the network modifiers because of its influence in the optical, electrical, and magnetic properties of the glass produced causing the glass to be environment-friendly and of low cost which grabs the attention of researches and manufacturing industry $[12,13]$. Silicate glass doped with high concentration of $\mathrm{ZnO}$ has lower elastic moduli because of the effect presented by $\mathrm{ZnO}$ which acts as a network modifier and its effect is what causes these types of glass to be outstanding compared to other types of glass system [14].

In this study, $\mathrm{ZnO}$ and WRHA will be manipulated to study the physical and elastic properties of $\mathrm{ZnO}-\mathrm{SiO}_{2}$ glass and glass ceramic system. Influence of $\mathrm{ZnO}$ on its elastic moduli and comparison of elastic moduli obtained experimentally and elastic moduli obtained theoretically were also discussed.

\section{Experimental Details}

$\mathrm{RH}$ species used is the Oryza sativa (Asian rice) which can be found in majority of Asian countries and RH from this study is acquired from a local rice factory at Tanjung Karang, Selangor, Malaysia. RH samples used were just milled a day before the study and they are kept in an indoor compound to minimize possible unwanted contaminations from the surroundings. RH then is examined to remove sands and small rocks which jeopardize the study. Next, $\mathrm{RH}$ is then washed for several times to get rid of possible dirt and contaminations as it is in contact with sand and it is drenched in water for 2 hours in a vast plastic basin to have the dirt and sands sunken to the bottom of the plastic basin. $\mathrm{RH}$ which is clean and clear without contaminations will float on the surface and it is removed to a large plastic sieve to dry the RH with an aluminum foil on top of it to minimize contaminations from the surroundings as it will be left in the lab for 24 hours to dry at room temperature. After 24 hours, $\mathrm{RH}$ will be subsequently dried in the oven for 2 hours at $100^{\circ} \mathrm{C}$ for 24 hours to obtain a fully dried RH. After obtaining the dry $\mathrm{RH}, 500 \mathrm{~g}$ of the dried $\mathrm{RH}$ is transferred to a ceramic crucible and distributed evenly so that the combustion of $\mathrm{RH}$ to WRHA can be performed evenly. $\mathrm{RH}$ will be burned at $1000^{\circ} \mathrm{C}$ for 2 hours at a heating rate of $10^{\circ} \mathrm{C} / \mathrm{min}$ and the changes in color of the WRHA produced are observed. Ceramic crucible selected must be flat as it delivers a complete homogeneous burning of RH. The EDXRF measurement has been done to obtain the percentage of the oxide composition in the WRHA [16].

In this study WRHA is acquired to replace conventional silica in the formation of $\mathrm{ZnO}-\mathrm{SiO}_{2}$ glass and glass ceramic system chemical formula of $(\mathrm{ZnO})_{x}(\mathrm{WRHA})_{1-x}(x=0.55$, $0.60,0.65$, and $0.70 \mathrm{wt} . \%)$ was symbolized by S1, S2, S3, and S4, respectively, acquiring melt-quench technique. After mixing the samples, the mixture is then milled for 24 hours to ensure a fully homogenous mixture. Usually, melting silicate glass system would require up to $1700^{\circ} \mathrm{C}$ as it belongs to type of glass with high melting point but in this study, where the silica source is being manipulated by switching it to WRHA to form $\mathrm{ZnO}-\mathrm{SiO}_{2}$ glass system, a new method is being done with the lowest temperature at which $\mathrm{ZnO}-\mathrm{SiO}_{2}$ system can exist at $1450^{\circ} \mathrm{C}$ with 2 hours. After all the samples inside the crucible were successfully melted, the crucible was removed with a platinum clamp and the samples are transferred to a stainless steel mold which has been preheated at $500^{\circ} \mathrm{C}$ and the samples then are annealed at $500^{\circ} \mathrm{C}$ for 5 hours while the leftover samples were transferred into the same stainless steel base which holds the mold and is annealed the similar condition. Finally the samples were cut using a diamond blade cutter to a dimension of $(1.0 \times 2.0 \times 0.3) \mathrm{cm}^{3}$ and later the samples were grinded using several grinding papers in the range of 320-1000 grit to ensure a perfect smooth surface for ultrasonic measurement. Samples thickness of $(1.0 \times 2.0$ $\times 0.3) \mathrm{cm}^{3}$ is the optimum thickness because samples which are too thick or too thin may cause the decrease in ultrasonic wave intensity.

The compositions of the glass and glass ceramic samples are confirmed using EDXRF diffractometer (Shimadzu, EDX-720). Next, the densities of the samples were determined using the Archimedes method where it acquires the weight of the samples in air and distilled water. Based on the Archimedes method, the buoyant force produced when the sample is immersed in distilled water is the same with the magnitude of the weight of distilled water displaced by the volume of the samples. Hence, the density of samples, $\rho_{\text {sample }}$, can be expressed as

$$
\begin{aligned}
& \rho_{\text {sample }} \\
& =\frac{\text { weight of sample in air }}{\text { weight of sample in air }- \text { weight of sample in distilled water }} \\
& \quad \times \rho_{\text {distilled water }},
\end{aligned}
$$

where $\rho_{\text {distilled water }}=1.000 \mathrm{~g} \mathrm{~cm}^{-3}$. Distilled water was chosen as the immersed liquid as it is the cheap, inert, and low surface tension. Molar volume $\left(V_{m}\right)$ of any substance is defined as the volume occupied by one mole of any material from chemical compound or chemical element at a specified temperature and pressure formula of $V_{m}$ is equal to the total molar mass $(M)$ divided by the mass density $(\rho)$.

The molar volumes were measured in cubic centimeters per mole $\left(\mathrm{cm}^{3} \mathrm{~mol}^{-1}\right)$ and for liquids and solids; they can be expressed as

$$
V_{m}=\sum \frac{M_{T}}{\rho},
$$

where $M_{T}$ is the total molecular weight of the multicomponent system given by

$$
M_{T}=x_{i} Z_{i}
$$

where $x_{i}$ is the mole fraction of the $i$ th oxides, and $Z_{i}$ is the molecular weight of the $i$ th oxides. Ultrasonic velocities of 
TABLE 1: Analysis of chemical composition of $\mathrm{ZnO}-\mathrm{SiO}_{2}$ samples.

\begin{tabular}{lcccccccrr}
\hline Samples & $\mathrm{ZnO}$ & $\mathrm{SiO}_{2}$ & $\mathrm{~K}_{2} \mathrm{O}$ & $\mathrm{Al}_{2} \mathrm{O}_{3}$ & $\mathrm{CaO}$ & $\mathrm{MgO}$ & $\mathrm{Na}_{2} \mathrm{O}$ & $\mathrm{Fe}_{2} \mathrm{O}_{3}$ & $\mathrm{CuO}^{2}$ \\
\hline $\mathrm{S} 1$ & 53.83 & 43.02 & 0.84 & 0.75 & 0.59 & 0.26 & 0.24 & 0.25 & 0.22 \\
$\mathrm{~S} 2$ & 58.40 & 38.84 & 0.78 & 0.66 & 0.58 & 0.23 & 0.20 & 0.22 & 0.09 \\
$\mathrm{~S} 3$ & 65.01 & 32.46 & 0.74 & 0.61 & 0.56 & 0.21 & 0.19 & 0.20 & 0.02 \\
S4 & 70.02 & 28.68 & 0.44 & 0.34 & 0.29 & 0.07 & 0.10 & 0.05 & 0.01 \\
\hline
\end{tabular}

TABLE 2: Density, molecular weight, and molar volumeof $\mathrm{ZnO}-\mathrm{SiO}_{2}$ samples.

\begin{tabular}{lcccc}
\hline Samples & S1 & S2 & S3 & \\
\hline Density $\left(\mathrm{g} \mathrm{cm}^{-3}\right)$ & 2.94 & 3.08 & 3.44 & 3.66 \\
$M_{T}\left(\mathrm{~g} \mathrm{~mol}^{-1}\right)$ & 70.43 & 71.59 & 72.79 & 73.91 \\
$V_{m}\left(\mathrm{~cm}^{3} \mathrm{~mol}^{-1}\right)$ & 23.97 & 23.21 & 21.17 & 20.18 \\
\hline
\end{tabular}

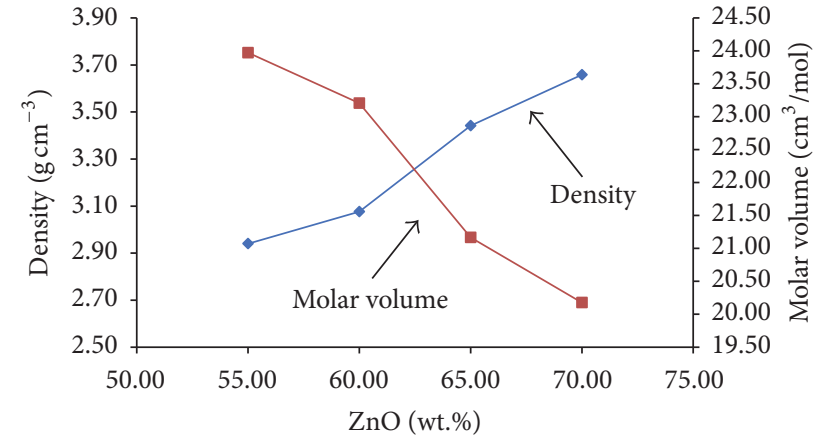

FIgURE 1: The density and molar volume versus wt.\% of $\mathrm{ZnO}$ in $\mathrm{ZnO}-\mathrm{SiO}_{2}$ samples.

the samples which consist of longitudinal velocity $\left(V_{L}\right)$ and shear velocity $\left(V_{S}\right)$ were determined using Ritec, Ram-5000 Snap System machine with frequency of $5 \mathrm{MHz}$. Longitudinal velocity of the samples was acquired using the longitudinal probe while the shear velocity of the samples was acquired using the shear probe. Adhesive agent used for the longitudinal probe is longitudinal gel while the shear probe is shear gel. Adhesive agent is used to minimize the refraction of wave in air gap while acquiring both ultrasonic velocities.

Ultrasonic technique is a method that is useful and flexible to measure the structure and mechanical properties of materials. Next, ultrasonic waves can be transmitted through the material and detect the mechanical properties and the defects found in the material. Generally, ultrasonic measurement can be used to measure the metal and nonmetal samples. Ultrasonic pulse-echo technique can also be known as the longitudinal modulus and shear modulus.

\section{Results and Discussion}

Four series of $\mathrm{ZnO}-\mathrm{SiO}_{2}$ samples were obtained and chemical composition of the WRHA was analyzed using EDXRF and the chemical composition of the WRHA and samples produced was tabulated in Table 1.

Figure 1 and Table 2 show the density, molecular weight, and molar volume for $\mathrm{ZnO}-\mathrm{SiO}_{2}$ samples and it shows that the density of the samples increases with the increase of

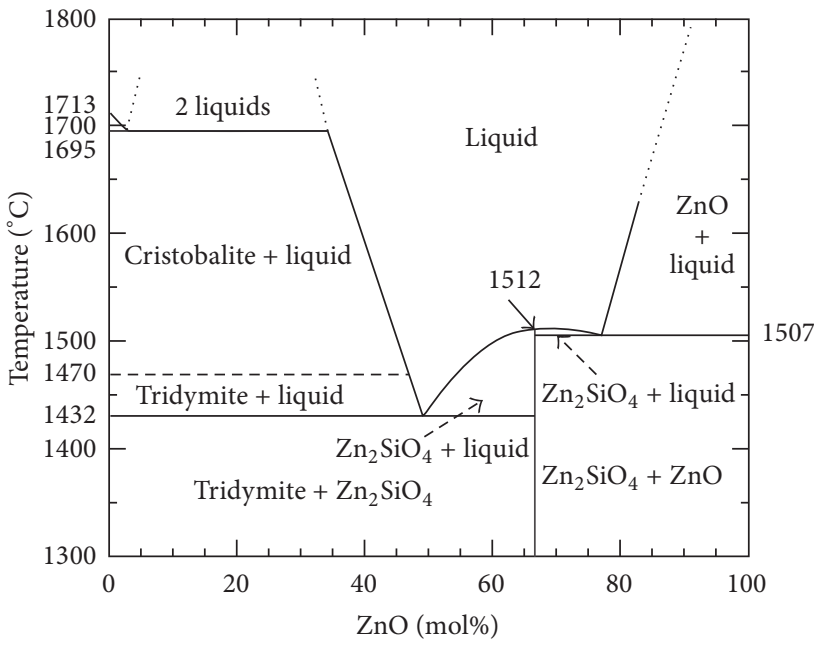

Figure 2: Binary system of $\mathrm{ZnO}-\mathrm{SiO}_{2}$ system [15].

$\mathrm{ZnO}$ from 2.94 to $3.66 \mathrm{~g} \mathrm{~cm}^{-1}$. Increase in density is largely due to substituting $\mathrm{Si}$ (28.08) with a higher atomic mass element of zinc which is (65.39). Besides, the increase in density with the increase of $\mathrm{ZnO}$ content occurs due to the increase in the crystallinity in the samples in which sample S1 is fully amorphous and sample S4 provides higher amounts of crystalline compared to the other samples [17, 18]. Increase in crystallinity is due to the increase in melting point of the $\mathrm{ZnO}-\mathrm{SiO}_{2}$ samples as its melting point increases as $\mathrm{ZnO}$ in the system increases as shown in Figure 2. Not only that, silica present in the system will also act as a nucleating agent for the samples to increase in crystalline [15].

Increase in density can also be explained by the increase in $\mathrm{ZnO}$ and the reduction of silica $\left(\mathrm{SiO}_{2}\right)$ which will increase its overall molecular weight of the samples as $\mathrm{ZnO}$ is much heavier relative to molecular mass of $\mathrm{SiO}_{2}$ [19]. Increase in density of the $\mathrm{ZnO}-\mathrm{SiO}_{2}$ samples may also be caused by structural reorganization of the atoms thus causing a possible modification of the geometrical configuration.

Molar volume $\left(V_{m}\right)$ in this study was calculated using (2) and, based on Figure 1 and Table 2, molar volumes of the $\mathrm{ZnO}-\mathrm{SiO}_{2}$ samples produced indicate a decrease from 23.97 to $20.18 \mathrm{~cm}^{3} \mathrm{~mol}^{-1}$ when the amount of $\mathrm{ZnO}$ in the 
TABLE 3: Density, molar volume, molecular weight, and ultrasonic velocity of $\mathrm{ZnO}-\mathrm{SiO}_{2}$ samples.

\begin{tabular}{lcccc}
\hline Samples & S1 & S2 & S3 & \\
\hline Density $\left(\mathrm{g} \mathrm{cm}^{-3}\right)$ & 2.94 & 3.08 & 3.44 & 3.66 \\
$V_{m}\left(\mathrm{~cm}^{3} \mathrm{~mol}^{-1}\right)$ & 23.97 & 23.21 & 21.17 & 20.18 \\
$M_{T}\left(\mathrm{~g} \mathrm{~mol}^{-1}\right)$ & 70.43 & 71.59 & 72.79 & 73.91 \\
$V_{L}\left(\mathrm{~ms}^{-1}\right)$ & 3857.03 & 3609.90 & 2794.69 & 2482.31 \\
$V_{S}\left(\mathrm{~ms}^{-1}\right)$ & 1951.95 & 1611.21 & 1185.46 & 966.27 \\
\hline
\end{tabular}

samples increases. Molar volume is vastly dependent on the overall molecular weight of a particular composition and this decrease is mainly because of greater rise in density compared to the overall molecular weight. Generally, silicate glass and glass ceramic have an opposite trend to the density of its system when it comes to the molar volume and, in this study, $\mathrm{SiO}^{2+}(0.038 \mathrm{~nm})$ which is greater in ionic radius is substituted with $\mathrm{Zn}^{2+}(0.074 \mathrm{~nm})$ thus causing the increase in the interatomic spacing or bond length between the atoms [20]. Besides that, the overall reduction in the interatomic distances will result in the increase of compactness of the glass matrix [21].

Decrease in $V_{m}$ can also be attributed to the addition of $\mathrm{ZnO}$ as it causes some kind of structural rearrangement of the atoms by entering the glass system and destroying the $\mathrm{Si}-\mathrm{O}-\mathrm{Si}$ bonds, thus creating ionic bonds between $\mathrm{Zn}^{2+}$ and single bonded oxygen atoms [20]. Next, there is also a possibility for the modification of the geometrical configuration upon swapping $\mathrm{ZnO}$ into the glass network and the structure of the studied glasses will not be expanded, which have more compact and low number of covalent bonds with high reduction in the number of bridging oxygens (BOs) [22]. Longitudinal velocity $\left(V_{L}\right)$ and the shear velocity $\left(V_{S}\right)$ of the samples were acquired and are presented in Table 3 and were plotted in Figure 3. Generally, $V_{L}$ and $V_{S}$ of majority of materials will increase as the density of the system increases but, for this study, $V_{L}$ and $V_{S}$ decrease as the density of the system increases. Similar trends were also observed for soda lime silicate and silicate glass system whereby the $V_{L}$ and $V_{S}$ of the samples decrease when the density in the sample increases [23]. Decrease in $V_{L}$ and $V_{S}$ of the samples is due to rise in amount of $\mathrm{ZnO}$ present in the samples which contains $\mathrm{Zn}^{2+}$ ions where its zinc atom had higher atomic radius compared to $\mathrm{Si}$ atom therefore encouraging the transformation of $\mathrm{BOs}$ to NBOs in the system.

Based on Table 3, values of $V_{S}$ are much smaller compared to the value of its counterpart $V_{L}$ and it can be considered half of the value of $V_{L}$ at the same compositions. For example, sample $S 1$ which has a value of $V_{S}$ is $1951.95 \mathrm{~ms}^{-1}$ while its $V_{L}$ is $3857.03 \mathrm{~ms}^{-1}$ which shows that its shear velocity is half of the longitudinal velocity and the trend is constant throughout all samples. Next, the values of $V_{L}$ decrease from $3857.03 \mathrm{~ms}^{-1}$ to $2482.31 \mathrm{~ms}^{-1}$ while $V_{S}$ decreases from $1951.95 \mathrm{~ms}^{-1}$ to $966.27 \mathrm{~ms}^{-1}$ as the amount of $\mathrm{ZnO}$ increases. Increase in the amount of $\mathrm{ZnO}$ in the samples promotes the formation of NBOs and it is because $\mathrm{ZnO}$ which acts as a network former and $\mathrm{Zn}^{2+}$ ions are the main result which causes the increase in NBOs. In the glass system, average coordination number of

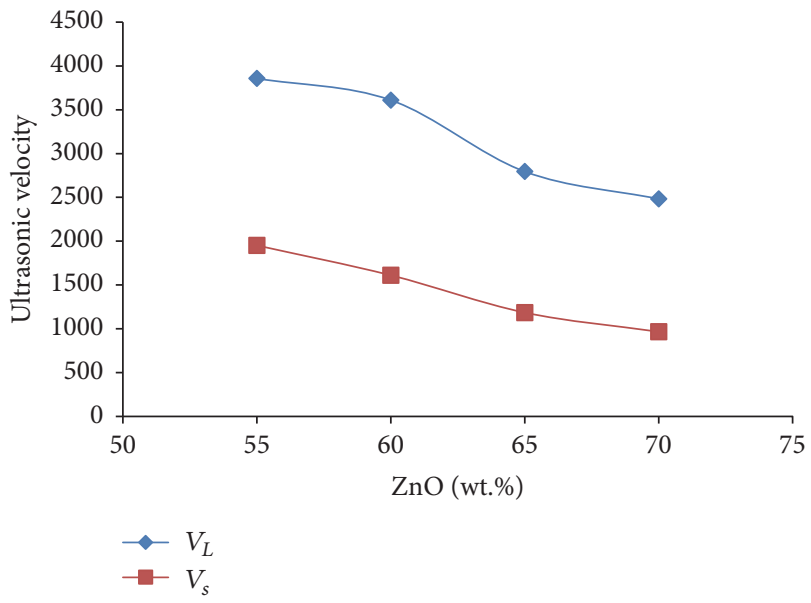

FIGURE 3: Longitudinal and shear velocity versus wt.\% of $\mathrm{ZnO}$ in $\mathrm{ZnO}-\mathrm{SiO}_{2}$ samples.

$\mathrm{SiO}_{2}$ gradually reduced to 3 from 4 as the values of $\mathrm{ZnO}$ rise and this causes the structural units of $\mathrm{SiO}_{4}$ to be converted to $\mathrm{SiO}_{3}$ initiating the rise of NBOs [24-26]. Decrease in both $V_{L}$ and $V_{S}$ with the rise of $\mathrm{ZnO}$ also indicates that the ultrasonic wave encounters more resistance in the $\mathrm{ZnO}-\mathrm{SiO}_{2}$ samples as the amount of $\mathrm{ZnO}$ increases [27, 28]. Not only that, rise of $\mathrm{ZnO}$ in the $\mathrm{ZnO}-\mathrm{SiO}_{2}$ samples also indicates that more $\mathrm{Zn}^{2+}$ ions exist in the samples and this caused overall more ions in samples to be opened up [29]. A result of lower ultrasonic velocity at higher content of $\mathrm{ZnO}$ indicates a major alteration in the structures of the samples.

Experimental values of longitudinal modulus $(L)$, shear modulus $(S)$, Young's modulus $(E)$, bulk modulus $(K)$, Poisson's ratio $(\sigma)$, fractal bond connectivity $(d)$, and microhardness $(H)$ were calculated from the data obtained by ultrasonic velocities. The results of the elastic properties of the $\mathrm{ZnO}-\mathrm{SiO}_{2}$ samples are shown in Table 4. As seen, from Table 4 , all the values of the elastic moduli decrease with the rise in $\mathrm{ZnO}$.

Longitudinal modulus and shear modulus can be defined as an independent elastic constant which are produced by a small stress such as the elastic strain in an amorphous solid [30]. Longitudinal modulus is $L=\rho V_{L}^{2}$ and for pure shear modulus it is $S=\rho V_{S}^{2}$, where $V_{L}$ and $V_{S}$, respectively, are the longitudinal and shear velocities of the samples [31]. The longitudinal modulus $(L)$, shear modulus $(S)$, Young's modulus $(E)$, bulk modulus $(K)$, Poisson's ratio $(\sigma)$, and microhardness can be obtained using the ultrasonic velocities 
TABLE 4: Experimental longitudinal modulus $(L)$, shear modulus $(S)$, Young's modulus $(E)$, bulk modulus $(K)$, Poisson's ratio $(\sigma)$, fractal bond connectivity $(d)$, and microhardness $(H)$ of $\mathrm{ZnO}-\mathrm{SiO}_{2}$ samples.

\begin{tabular}{lccccccc}
\hline Samples & $L(\mathrm{GPa})$ & $S(\mathrm{GPa})$ & $E(\mathrm{GPa})$ & $K(\mathrm{GPa})$ & $\sigma$ & $d=4 \mathrm{G} / K$ & \\
\hline S1 & 43.74 & 11.20 & 29.75 & 28.80 & 0.3279 & 1.5557 & 1.0851 \\
S2 & 40.10 & 7.99 & 21.98 & 29.45 & 0.3756 & 1 \\
S3 & 26.88 & 4.84 & 13.45 & 20.43 & 0.3903 & 0.9469 \\
S4 & 22.54 & 3.42 & 9.64 & 17.99 & 0.4107 & 0.7596 & 5.438 \\
\hline
\end{tabular}

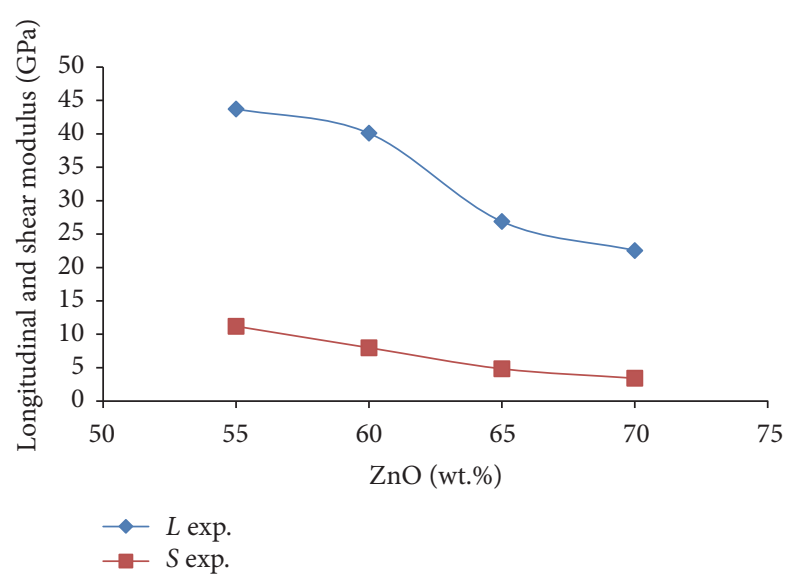

FIGURE 4: Longitudinal and shear modulus versus wt.\% of $\mathrm{ZnO}$ in $\mathrm{ZnO}-\mathrm{SiO}_{2}$ samples.

by acquiring these equations from the following journals by Laoding et al. (2016) and Sidek et al. (2016) [32,33]. Based on Table 4 and Figure 4 which illustrate the values and plot of longitudinal modulus and shear modulus of the $\mathrm{ZnO}-\mathrm{SiO}_{2}$ samples, it can be seen that as the amount of $\mathrm{ZnO}$ in the samples increases, the longitudinal modulus and shear modulus decrease. Decrease in longitudinal modulus from samples S1 to $\mathrm{S} 4$ is from $43.74 \mathrm{GPa}$ to $22.54 \mathrm{GPa}$ while decrease in shear modulus from samples $\mathrm{S} 1$ to $\mathrm{S} 4$ is from $11.20 \mathrm{GPa}$ to $3.42 \mathrm{GPa}$. Longitudinal modulus for every sample is higher compared to its counterpart of shear modulus for every sample from S1 to S4 and this implies that the sample can withstand longitudinal stress compared to shear stress which indicates the samples are easier to be bent than elongated.

Young's modulus is defined as the ratio of stress against strain and it also represents the stiffness in a particular material which links to bonding strength between atoms in materials. Materials which have higher value of Young's modulus imply that that particular material is more stiffer and this Young's modulus is also affected by the dimensionality and connectivity of the system [33]. Not only that, samples that have higher value of Young's modulus can endure more stress compared to samples which possess lower Young's modulus and Figure 5 shows that as the amount of $\mathrm{ZnO}$ in the samples increases, Young's modulus of the samples decreases which indicates the increase in number of NBOs [34]. Decrease in the NBOs further links to the decrease in connectivity of the samples network which is caused by the decrease in Young's modulus. Lower Young's modulus as

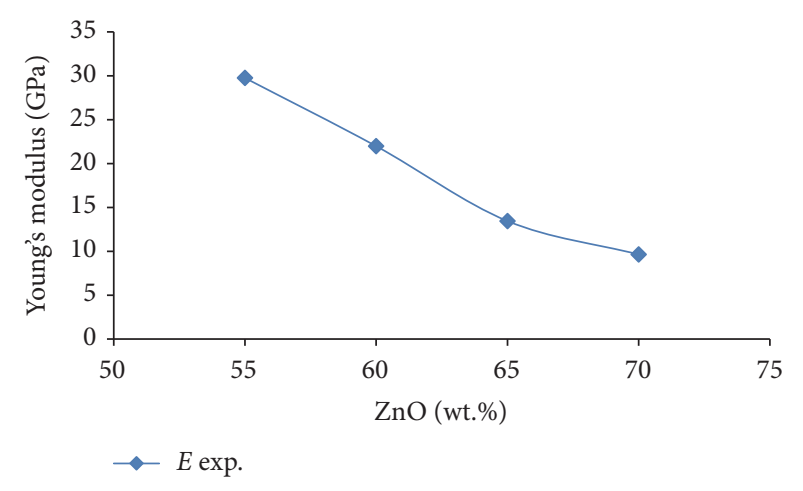

FIgURE 5: Young's modulus versus wt.\% of $\mathrm{ZnO}$ in $\mathrm{ZnO}-\mathrm{SiO}_{2}$ samples.

$\mathrm{ZnO}$ increases shows that the $\mathrm{ZnO}-\mathrm{SiO}_{2}$ samples can reduce the speed of impacting mass thus causing a smaller stress compared to samples which have higher Young's modulus [34]. Results of Young's modulus can indicate that the samples can bear small stress acting against it even though its structure is less rigid and the decrease in Young's modulus indicates that the samples can work well with strain.

Bulk modulus $(K)$ is known as the alteration in volume of a material when a small or moderate force is performed upon the specific surface. Figure 6 shows that as the amount of $\mathrm{ZnO}$ in the system increases, the bulk modulus of the samples increases and the bulk modulus of the samples is higher compared to Young's modulus which indicates that the samples work well with stress from multiple directions but not in one direction. Hence this clearly means that glass and glass ceramic acquired are usually hard if stress is applied from numerous directions simultaneously but would fracture if stress is applied at a single direction. Bergman and Kantor (1984) proposed the analysis of fractal bond connectivity with ratio of bulk to shear modulus and it can be simplified as $d=$ $4 S / K$ where it gives the effective dimensionality of particular materials for any nonhomogeneous random mixture of fluid and a solid backbone near the percolation limit [35]. Value of $d=4 S / K$ acts as a parameter for network connectivity with a range of values obtained by the ratio [36]. Values of $d$ differ for each kind of materials subjected on its dimension and $d=1$ is for $1 \mathrm{D}$ chain and $d=2$ and $d=3$ for $2 \mathrm{D}$ and 3D chain structures correspondingly [37-39]. Results shown in Figure 7 and Table 4 indicate that the fractal bond connectivity of the $\mathrm{ZnO}-\mathrm{SiO}_{2}$ samples ranges from 0 to 1 which shows that $\mathrm{ZnO}-\mathrm{SiO}_{2}$ samples possess a $1 \mathrm{D}$ layer structure [40]. As $\mathrm{ZnO}$ increases in the samples, fractal bond 


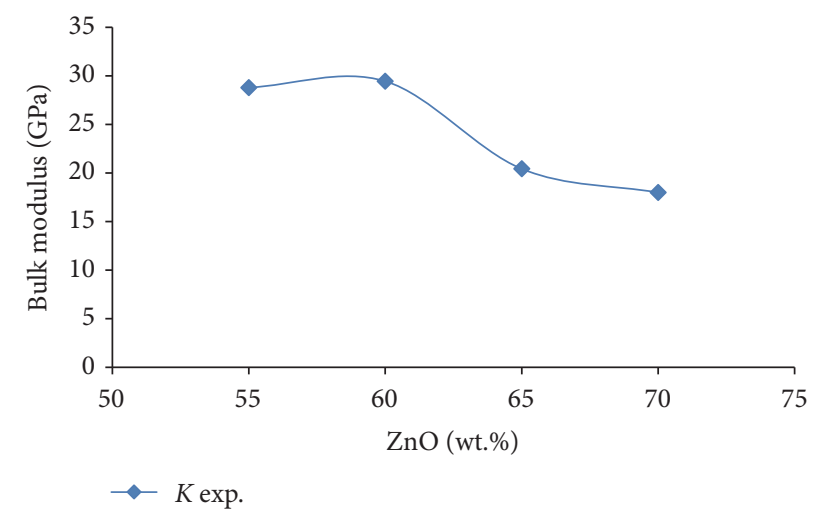

Figure 6: Bulk modulus versus wt.\% of $\mathrm{ZnO}$ in $\mathrm{ZnO}-\mathrm{SiO}_{2}$ samples.

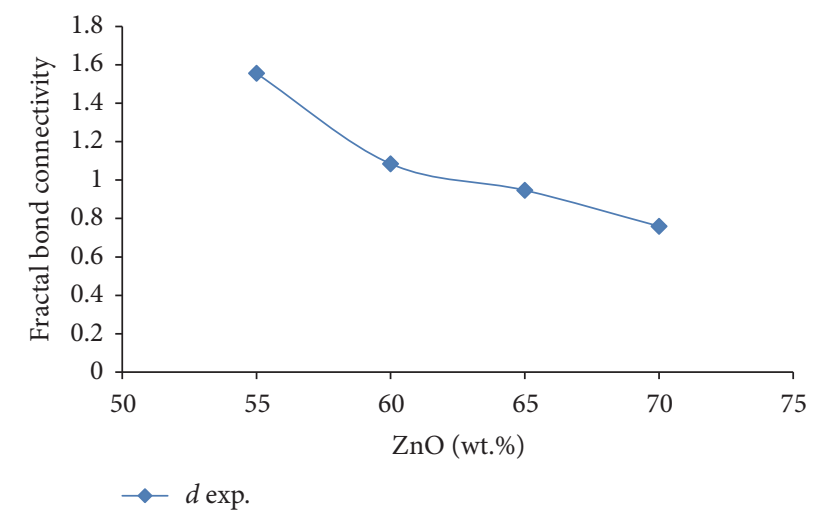

Figure 7: Fractal bond connectivity versus wt.\% of $\mathrm{ZnO}$ in $\mathrm{ZnO}-\mathrm{SiO}_{2}$ samples.

connectivity decreases and this will cause cross-links of the samples to be weakened and possibly break [23].

Poisson ratio is the measure of ratio of the shear strain to the longitudinal strain when tensile force is applied and it makes use of the degree of cross-link density of glass and glass ceramic network to find out the order of cross-link density [41]. Poisson's ratio measures the capability of a material to counter the alteration in volume when an incoming load acts on a certain material and the Poisson ratio $(v)$ acquired can be in positive or negative [42]. In this study it is in the range of 0.327 to 0.410 .

From Figure 8, it is observed that, as $\mathrm{ZnO}$ increases in the samples, results in higher values of Poisson's ratio show that the samples have a lower resistance towards lateral expansion when compressed compared to samples with lower amount of $\mathrm{ZnO}$. Rise in Poisson's ratio also shows that the decrease in cross-link density and lateral strength with the increase in $\mathrm{ZnO}$ as network former does not have much significance in its cross-link density [43]. Relationship between Poisson's ratio and cross-link density was first discussed by Bridge et al. (1983) and its relationship is known as the number of bridging bonds per cations in the structure of the system where results of the cross-link density 0,1 , and 2 are associated with the values of Poisson's ratio obtained, $0.40,0.30$, and 0.15 , correspondingly [44]. Average value of Poisson's ratio

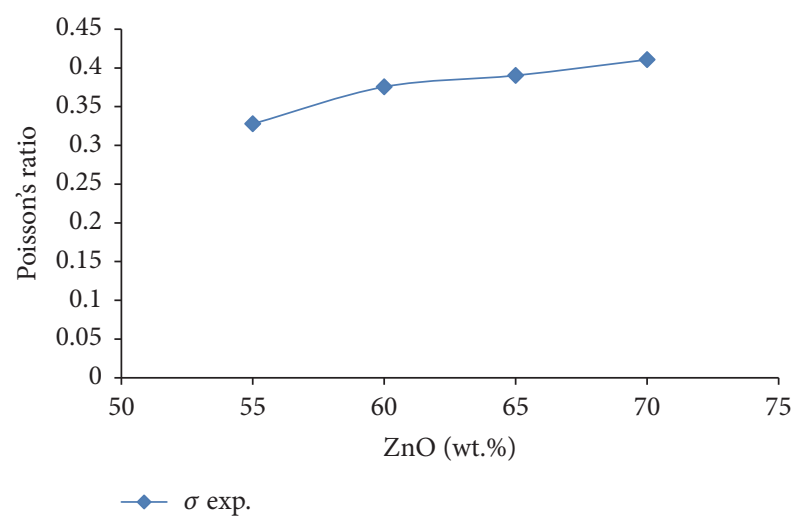

Figure 8: Poisson's versus wt.\% of $\mathrm{ZnO}$ in $\mathrm{ZnO}-\mathrm{SiO}_{2}$ samples.

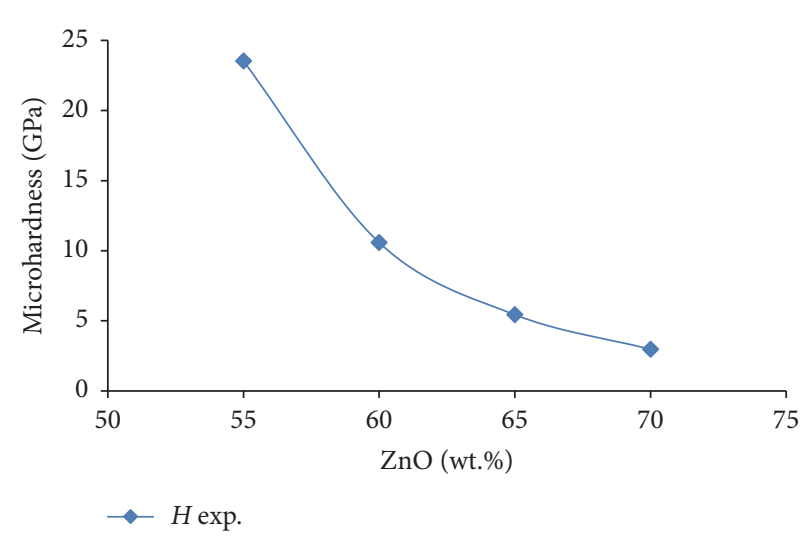

Figure 9: Microhardness versus wt.\% of $\mathrm{ZnO}$ in $\mathrm{ZnO}-\mathrm{SiO}_{2}$ samples.

acquired in these samples is 0.34 which suggests that the samples have 1D layer structure and values of this result correlate with the results from fractal bond connectivity which is around 1.

Microhardness $(H)$ is known to be the total stress which is necessary to remove the free volume or distortion of the glass and glass ceramic network [45]. Based on Figure 9, the microhardness of the samples decreases as the amount of $\mathrm{ZnO}$ increases in the system and indicates a decrease in the connectivity of the glass and glass ceramic system. Application of hydrostatic pressure is necessary to decrease the free volume in the glass and glass ceramic system [46].

After completing experimental elastic moduli, it is always interesting to predict the results of elastic moduli without performing experimental methods. Theory of elastic prediction has been brought up by Makishima and Mackenzie $(1973,1975)$ on the prediction of elastic moduli of oxide glass by utilizing composition of oxides and packing density of chemical composition of the glass $[47,48]$.

Rocherulle et al. (1989) improved the packing density of the equation approximately 20 years later and incorporated $\mathrm{A}_{m} \mathrm{O}_{n}$ as

$$
C_{i}=\left(6.023 \times 10^{23}\right) \frac{4}{3} \pi\left(\frac{\rho}{M}\right)\left(m R_{\mathrm{A}}^{3}+n R_{\mathrm{O}}^{3}\right)
$$


TABLE 5: Theoretical calculated total packing density, elastic moduli, and Poisson's ratio of $\mathrm{ZnO}-\mathrm{SiO}_{2}$ samples.

\begin{tabular}{|c|c|c|c|c|c|c|}
\hline \multirow{2}{*}{ Sample } & \multirow{2}{*}{$C_{t}$} & \multicolumn{5}{|c|}{ Theoretical elastic moduli and Poisson's ratio } \\
\hline & & $L_{\text {cal }}(\mathrm{GPa})$ & $S_{\text {cal }}(\mathrm{GPa})$ & $E_{\text {cal }}(\mathrm{GPa})$ & $K_{\mathrm{cal}}(\mathrm{GPa})$ & $\sigma_{\mathrm{cal}}$ \\
\hline S1 & 0.5851 & 46.53 & 15.57 & 36.83 & 25.78 & 0.2626 \\
\hline S2 & 0.5819 & 44.96 & 15.10 & 35.68 & 24.83 & 0.2613 \\
\hline S3 & 0.5770 & 42.68 & 14.41 & 34.00 & 23.46 & 0.2592 \\
\hline S4 & 0.5731 & 40.93 & 13.88 & 32.71 & 22.42 & 0.2576 \\
\hline
\end{tabular}

where $R_{\mathrm{A}}$ and $R_{\mathrm{O}}$ are Pauling's ionic radius of cation $\mathrm{A}$ and anions $\mathrm{O}, \rho$ and $M$ are the density and effective molecular weight, and $C_{i}$ is the new packing density [49]. This model offers a new derivation of elastic moduli and Poisson ratio's for the current system as

$$
\begin{aligned}
L_{\mathrm{cal}} & =\left[100+\frac{4}{3}\left(\frac{300}{10.2 C_{t}-1}\right)\right] C_{t}^{2} \sum_{i} G_{i} x_{i}, \\
S_{\mathrm{cal}} & =\left[\frac{300 C_{t}^{2}}{10.2 C_{t}-1}\right] \sum_{i} G_{i} x_{i}, \\
E_{\mathrm{cal}} & =83.6 C_{t} \sum_{i} G_{i} x_{i}, \\
K_{\mathrm{cal}} & =100 C_{t}^{2} \sum_{i} G_{i} x_{i}, \\
\sigma_{\mathrm{cal}} & =0.5-\frac{1}{7.2 C_{t}}, \\
G_{t} & =\sum_{i} G_{i} x_{i}, \\
C_{t} & =\sum_{i} C_{i} x_{i},
\end{aligned}
$$

where $C_{t}, G_{t}, G_{i}$, and $x_{i}$ are the total packing density, total dissociation energy per unit volume, dissociation energy per unit volume, and the mole fraction of the oxide $i$ th component correspondingly.

Table 5 illustrates the theoretical calculated total packing density, $C_{t}$, longitudinal modulus, $L_{\text {cal }}$, shear modulus, $S_{\text {cal }}$, Young's modulus, $E_{\text {cal }}$, bulk modulus, $K_{\text {cal }}$, and Poisson's ratio, $\sigma_{\text {cal }}$, based on Rocherulle's model. Based on the values of theoretical elastic moduli and Poisson's ratio of $\mathrm{ZnO}-\mathrm{SiO}_{2}$ samples obtained, it can be observed that the all the theoretical elastic moduli and Poisson's ratio decrease when composition of $\mathrm{ZnO}$ increases. Longitudinal modulus calculated decreases from $46.53 \mathrm{GPa}$ to $40.93 \mathrm{GPa}$, shear modulus decreases from $15.57 \mathrm{GPa}$ to $13.88 \mathrm{GPa}$, Young's modulus decreases from $36.83 \mathrm{GPa}$ to $32.71 \mathrm{GPa}$, bulk modulus decreases from 25.78 GPa to $22.42 \mathrm{GPa}$, and Poisson's ratio decreases from 0.2626 to 0.2576 . Decrease in elastic moduli and Poisson's ratio as $\mathrm{ZnO}$ increases suggests that $\mathrm{ZnO}$ would act as network modifier thus breaking BOs and converts it to NBOs which will decrease the connectivity and elastic moduli of the samples. Elastic moduli and Poisson's ratio predicted by using Rocherulle's model were illustrated in Figures 10 and 11. Comparisons of the experimental elastic moduli and Poisson's ratio and the theoretical elastic moduli and Poisson's

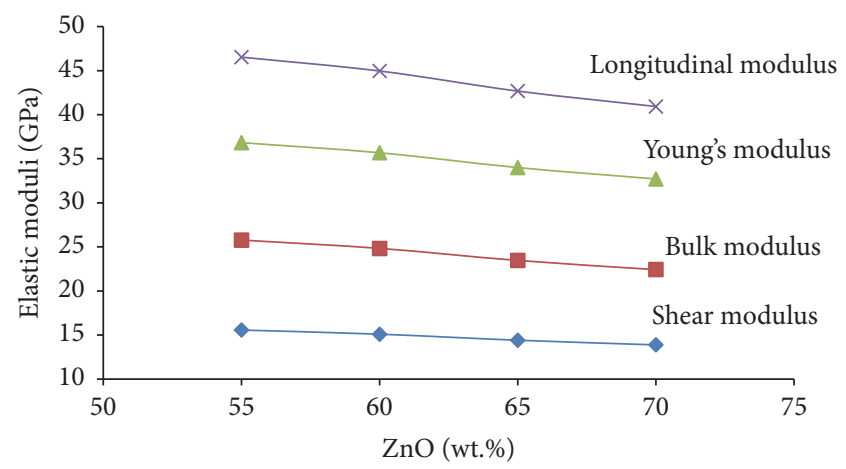

FIgURE 10: Elastic moduli versus wt.\% of $\mathrm{ZnO}$ calculated using Rocherulle's model.

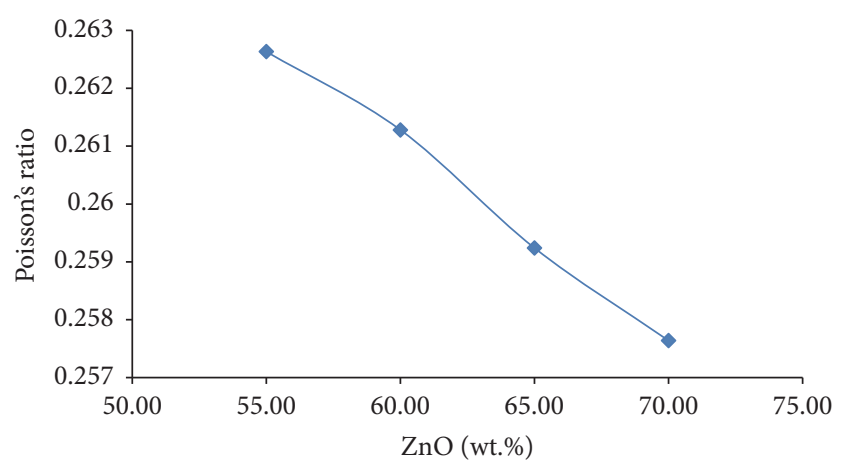

Figure 11: Poisson's ratio versus wt.\% of $\mathrm{ZnO}$ calculated using Rocherulle's model.

ratio were illustrated in Figures 12-16. Experimental elastic moduli and theoretical elastic moduli have a great agreement in similar trend but vary in value except for Poisson's ratio.

\section{Conclusion}

$(\mathrm{ZnO})_{x}(\mathrm{WRHA})_{1-x}(x=0.55,0.60,0.65$ and 0.70 wt.\%) was symbolized by S1, S2, S3, and S4, respectively, samples have been successfully fabricated, and the study of elastic moduli with prediction of its correlation with the variation of composition on physical and elastic characteristics of each sample was performed and analyzed. Physical analysis of the samples shows that as $\mathrm{ZnO}$ increases, the density of the overall samples decreases and this is very well associated with the formation of NBOs and its molar volume increases as $\mathrm{ZnO}$ increase which is caused by the substitution of ions of $\mathrm{Zn}^{2+}$ which is greater in interatomic spacing compared to $\mathrm{SiO}^{2+}$. 


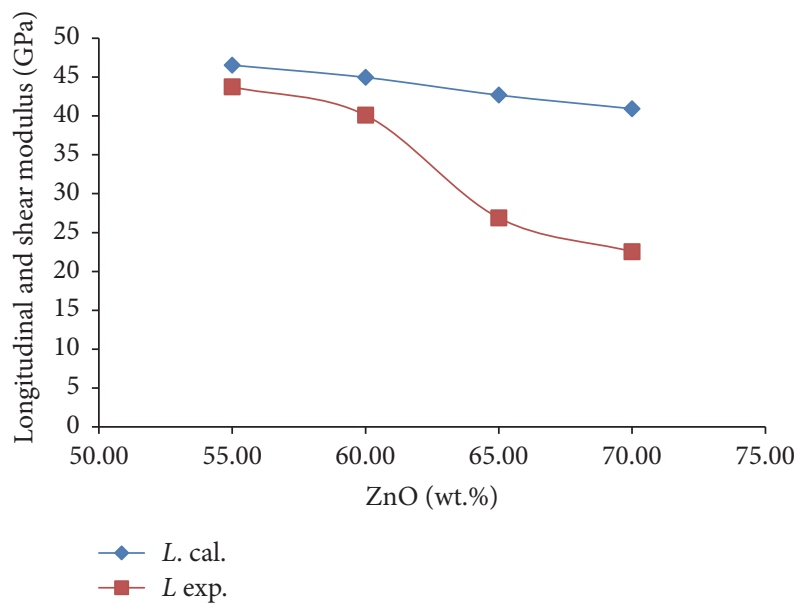

FIGURE 12: Experimental and theoretical longitudinal modulus versus wt.\% of $\mathrm{ZnO}$ in $\mathrm{ZnO}-\mathrm{SiO}_{2}$ samples.

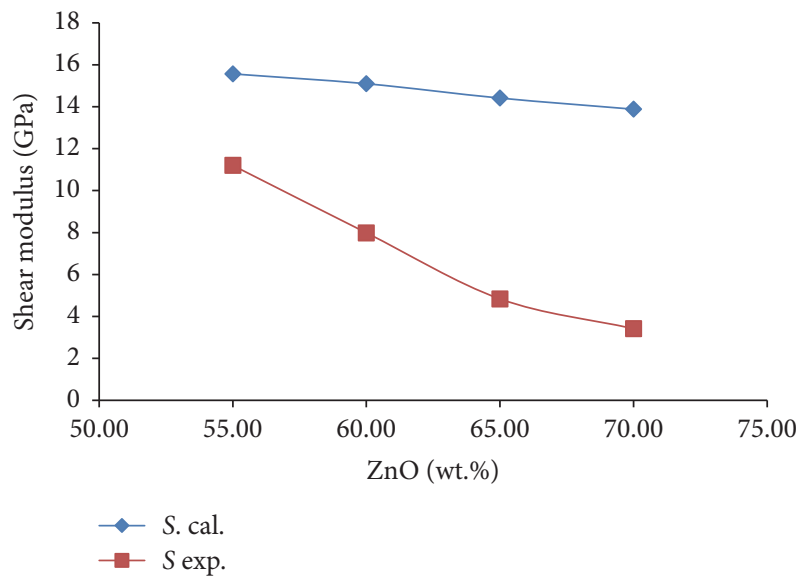

FIGURE 13: Experimental and theoretical shear modulus versus wt.\% of $\mathrm{ZnO}$ in $\mathrm{ZnO}-\mathrm{SiO}_{2}$ samples.

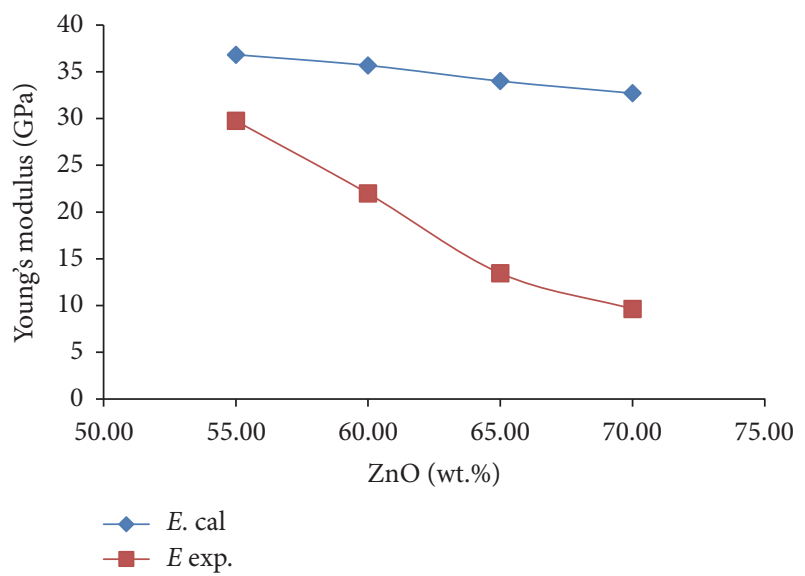

FIGURE 14: Experimental and theoretical Young's modulus versus wt. $\%$ of $\mathrm{ZnO}$ in $\mathrm{ZnO}-\mathrm{SiO}_{2}$ samples.

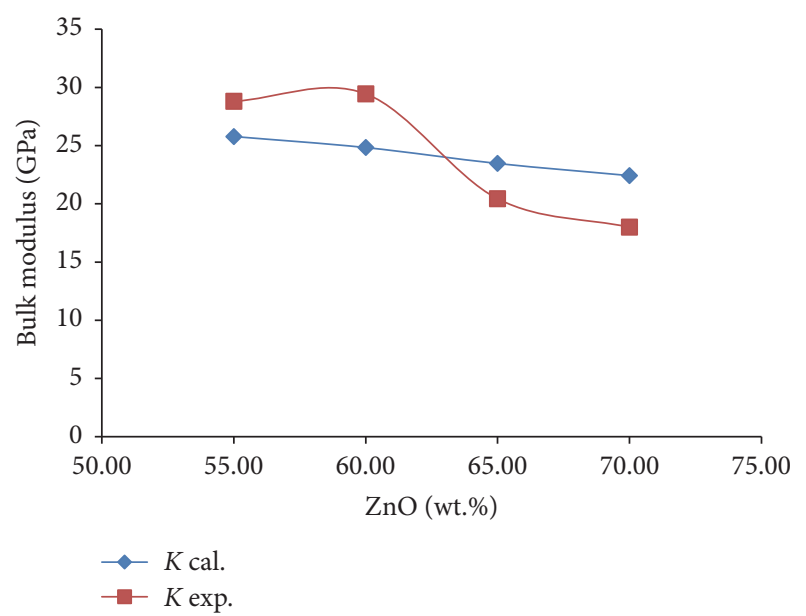

FIgURE 15: Experimental and theoretical bulk modulus versus wt.\% of $\mathrm{ZnO}$ in $\mathrm{ZnO}-\mathrm{SiO}_{2}$ samples.

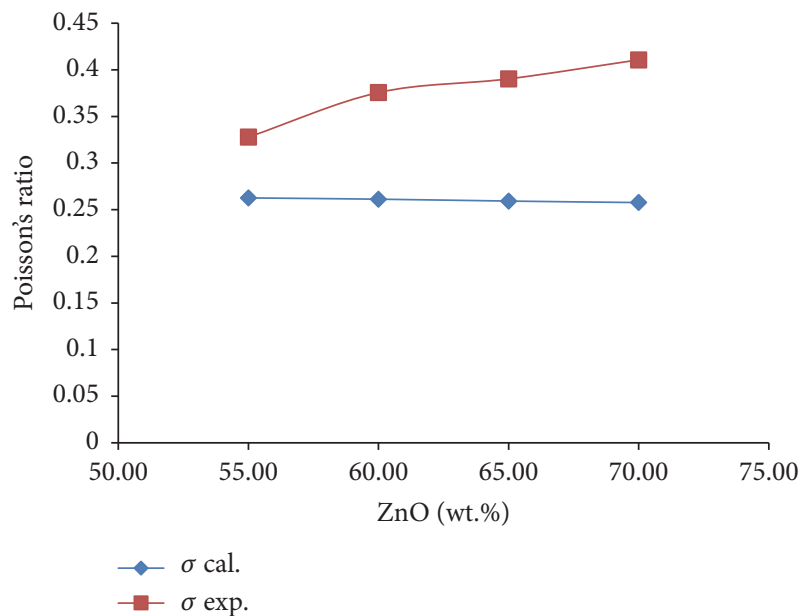

Figure 16: Experimental and theoretical Poisson's ratio versus wt.\% of $\mathrm{ZnO}$ in $\mathrm{ZnO}-\mathrm{SiO}_{2}$ samples.

Last but not least, all the theoretical elastic moduli possess the same trend as the elastic moduli obtained experimentally suggesting that $\mathrm{ZnO}$ would act as network modifier thus breaking $\mathrm{BOs}$ and converts it to NBOs which will decrease the connectivity and elastic moduli of the samples.

\section{Conflicts of Interest}

The authors declare that there are no conflicts of interest regarding the publication of this paper.

\section{Acknowledgments}

The researchers gratefully acknowledge the financial support for this study from the Malaysian Ministry of Higher Education (MOHE) and Universiti Putra Malaysia through the Fundamental Research Grant Scheme (FRGS) and Geran Putra Berimpak research grant. 


\section{References}

[1] A. M. Yusof, N. A. Nizam, and N. A. A. Rashid, "Hydrothermal conversion of rice husk ash to faujasite-types and NaA-type of zeolites," Journal of Porous Materials, vol. 17, no. 1, pp. 39-47, 2010.

[2] M. Ahmaruzzaman and V. K. Gupta, "Rice husk and its ash as low-cost adsorbents in water and wastewater treatment," Industrial \& Engineering Chemistry Research, vol. 50, no. 24, pp. 13589-13613, 2011.

[3] O. Mohiuddin, A. Mohiuddin, M. Obaidullah, H. Ahmed, and S. Asumadu-Sarkodie, "Electricity production potential and social benefits from rice husk, a case study in Pakistan," Cogent Engineering, vol. 3, no. 1, Article ID 1177156, 2016.

[4] M. Arabani, S. A. Tahami, and M. Taghipoor, "Laboratory investigation of hot mix asphalt containing waste materials," Road Materials and Pavement Design, vol. 18, no. 3, pp. 713-729, 2017.

[5] S. Kamari and F. Ghorbani, "Synthesis of magMCM-41 with rice husk silica as cadmium sorbent from aqueous solutions: parameters' optimization by response surface methodology," Environmental Technology (United Kingdom), pp. 1-18, 2016.

[6] S. A. Saad, M. F. Nuruddin, N. Shafiq, and M. Ali, "The effect of incineration temperature to the chemical and physical properties of ultrafine treated rice husk ash (UFTRHA) as supplementary cementing material (SCM)," in Proceedings of the 4th International Conference on Process Engineering and Advanced Materials, ICPEAM 2016, pp. 163-167, Kuala Lumpur, Malaysia, August 2016.

[7] B. O. Ayomanor and K. Vernon-Parry, "Potential synthesis of solar-grade silicon from rice husk ash," Solid State Phenomena, vol. 242, pp. 41-47, 2016.

[8] I. J. Fernandes, D. Calheiro, A. G. Kieling et al., "Characterization of rice husk ash produced using different biomass combustion techniques for energy," Fuel, vol. 165, pp. 351-359, 2016.

[9] F. A. Santos, C. dos Santos, D. Rodrigues Junior et al., "Lithium disilicate glass-ceramic obtained from rice husk-based silica," Advances in Science and Technology, vol. 63, no. 1, pp. 414-419, 2010.

[10] M. I. Martín, F. Andreola, L. Barbieri et al., "Crystallisation and microstructure of nepheline-forsterite glass-ceramics," Ceramics International, vol. 39, no. 3, pp. 2955-2966, 2013.

[11] M. H. M. Zaid, K. A. Matori, H. A. A. Sidek et al., "Fabrication and crystallization of $\mathrm{ZnO}$-SLS glass derived willemite glassceramics as a potential material for optics applications," Journal of Spectroscopy, vol. 2016, Article ID 8084301, 2016.

[12] X. L. Duan, D. R. Yuan, D. Xu et al., "Preparation and characterization of $\mathrm{Co}^{2+}$-doped $\mathrm{ZnO}-\mathrm{Al}_{2} \mathrm{O}_{3}-\mathrm{SiO}_{2}$ glass-ceramics by the sol-gel method," Materials research bulletin, vol. 38, no. 4, pp. 705-711, 2003.

[13] L. Yu and M. Nogami, "Local structure and photoluminescent characteristics of $\mathrm{Eu}^{3+}$ in $\mathrm{ZnO}-\mathrm{SiO}_{2}$ glasses," Journal of Sol-Gel Science and Technology, vol. 43, no. 3, pp. 355-360, 2007.

[14] K. A. Matori, M. H. M. Zaid, H. A. A. Sidek, M. K. Halimah, Z. A. Wahab, and M. G. M. Sabri, "Influence of $\mathrm{ZnO}$ on the ultrasonic velocity and elastic moduli of soda lime silicate glasses," International Journal of Physical Sciences, vol. 5, no. 14, pp. 2212-2216, 2010.

[15] E. N. Bunting, "Phase equilibria in the system $\mathrm{SiO}_{2}-\mathrm{ZnO}$," Journal of the American Ceramic Society, vol. 13, no. 1, pp. 5-10, 1930.
[16] A. J. A. Al-Nidawi, K. A. Matori, A. Zakaria, and M. H. M. Zaid, "Effect of $\mathrm{MnO}_{2}$ doped on physical, structure and optical properties of zinc silicate glasses from waste rice husk ash," Results in Physics, vol. 7, pp. 955-961, 2017.

[17] S. Zhang and A. Stamboulis, "Effect of zinc substitution for calcium on the crystallisation of calcium fluoro-alumino-silicate glasses," Journal of Non-Crystalline Solids, vol. 432, pp. 300-306, 2016.

[18] L. Chen and Y. Dai, "Structure, physical properties, crystallization and sintering of iron-calcium-aluminosilicate glasses with different amounts of ZnO," Journal of Non-Crystalline Solids, vol. 452, pp. 45-49, 2016.

[19] M. H. M. Zaid, K. A. Matori, H. J. Quah et al., "Investigation on structural and optical properties of SLS-ZnO glasses prepared using a conventional melt quenching technique," Journal of Materials Science: Materials in Electronics, vol. 26, no. 6, pp. 3722-3729, 2015.

[20] K. A. Matori, M. H. M. Zaid, H. J. Quah, H. A. A. Sidek, Z. A. Wahab, and M. G. M. Sabri, "Studying the effect of $\mathrm{ZnO}$ on physical and elastic properties of $(\mathrm{ZnO})_{x}\left(\mathrm{P}_{2} \mathrm{O}_{5}\right)_{1-x}$ glasses using nondestructive ultrasonic method," Advances in Materials Science and Engineering, vol. 2015, Article ID 596361, 2015.

[21] S. Y. Marzouk and M. S. Gaafar, "Ultrasonic study on some borosilicate glasses doped with different transition metal oxides," Solid State Communications, vol. 144, no. 10-11, pp. 478483, 2007.

[22] H. A. Saudi, H. A. Sallam, and K. Abdullah, "Borosilicate glass containing bismuth and zinc oxides as a hot cell material for gamma-ray shielding," Physics and Materials Chemistry, vol. 2, no. 1, pp. 20-24, 2014.

[23] M. H. M. Zaid, K. A. Matori, L. C. Wah et al., "Elastic moduli prediction and correlation in soda lime silicate glasses containing ZnO," International Journal of Physical Sciences, vol. 6, no. 6, pp. 1404-1410, 2011.

[24] N. A. Sharaf, R. A. Condrate Sr., and A. A. Ahmed, "FTIR spectral/structural investigation of the ion exchange/thermal treatment of silver ions into a silicate glass," Materials Letters, vol. 11, no. 3-4, pp. 115-118, 1991.

[25] P. F. Wang, Z. H. Li, J. Li, and Y. M. Zhu, "Effect of $\mathrm{ZnO}$ on the interfacial bonding between $\mathrm{Na}_{2} \mathrm{O}-\mathrm{B}_{2} \mathrm{O}_{3}-\mathrm{SiO}_{2}$ vitrified bond and diamond," Solid State Sciences, vol. 11, no. 8, pp. 1427-1432, 2009.

[26] A. Bernasconi, M. Dapiaggi, A. Pavese, G. Agostini, M. Bernasconi, and D. T. Bowron, "Modeling the structure of complex aluminosilicate glasses: The effect of zinc addition," Journal of Physical Chemistry B, vol. 120, no. 9, pp. 2526-2537, 2016.

[27] Y. B. Saddeek, E. R. Shaaban, K. A. Aly, and I. M. Sayed, "Characterization of some lead vanadate glasses," Journal of Alloys and Compounds, vol. 478, no. 1-2, pp. 447-452, 2009.

[28] M. M. Umair and A. K. Yahya, "Elastic and structural changes of $x \mathrm{Na}_{2} \mathrm{O}-(35-x) \mathrm{V}_{2} \mathrm{O}_{5}-65 \mathrm{TeO}_{2}$ glass system with increasing sodium," Materials Chemistry and Physics, vol. 142, no. 2-3, pp. 549-555, 2013.

[29] K. A. Matori, M. I. Sayyed, H. A. A. Sidek, M. H. M. Zaid, and V. P. Singh, "Comprehensive study on physical, elastic and shielding properties of lead zinc phosphate glasses," Journal of Non-Crystalline Solids, vol. 457, pp. 97-103, 2017.

[30] C. Bootjomchai, "Comparative studies between theoretical and experimental of elastic properties and irradiation effects of soda lime glasses doped with neodymium oxide," Radiation Physics and Chemistry, vol. 110, pp. 96-104, 2015. 
[31] C. Weigel, C. Le Losq, R. Vialla et al., "Elastic moduli of $\mathrm{XAlSiO}_{4}$ aluminosilicate glasses: effects of charge-balancing cations," Journal of Non-Crystalline Solids, vol. 447, pp. 267-272, 2016.

[32] H. Laoding, H. Mohamed Kamari, A. Zakaria, A. H. Shaari, and I. Mansor, "Elastic properties of thulium doped zinc borotellurite glass," Materials Science Forum, vol. 863, pp. 7074, 2016.

[33] H. A. A. Sidek, R. El-Mallawany, K. A. Matori, and M. K. Halimah, "Effect of $\mathrm{PbO}$ on the elastic behavior of $\mathrm{ZnO}-\mathrm{P}_{2} \mathrm{O}_{5}$ glass systems," Results in Physics, vol. 6, pp. 449-455, 2016.

[34] R. A. Mccauley, A. K. De, and D. S. Carr, "Improved impact resistance in soda-lime-silica glasses through zinc oxide substitutions," Journal of the American Ceramic Society, vol. 64, no. 11, pp. 157-158, 1981.

[35] D. J. Bergman and Y. Kantor, "Critical properties of an elastic fractal," Physical Review Letters, vol. 53, no. 6, pp. 511-514, 1984.

[36] K. Shinozaki, T. Honma, and T. Komatsu, "Elastic properties and Vickers hardness of optically transparent glass-ceramics with fresnoite $\mathrm{Ba}_{2} \mathrm{TiSi}_{2} \mathrm{O}_{8}$ nanocrystals," Materials Research Bulletin, vol. 46, no. 6, pp. 922-928, 2011.

[37] R. Bogue and R. J. Sladek, "Elasticity and thermal expansivity of $(\mathrm{AgI})_{x}\left(\mathrm{AgPO}_{3}\right)_{1-x}$ glasses," Physical Review B, vol. 42, no. 8, pp. 5280-5288, 1990.

[38] G. A. Saunders, T. Brennan, M. Acet et al., "Elastic and nonlinear acoustic properties and thermal expansion of cerium metaphosphate glasses," Journal of Non-Crystalline Solids, vol. 282, no. 2-3, pp. 291-305, 2001.

[39] N. Ghribi, M. Dutreilh-Colas, J.-R. Duclère et al., "Structural, mechanical and optical investigations in the $\mathrm{TeO}_{2}$-rich part of the $\mathrm{TeO}_{2}-\mathrm{GeO}_{2}-\mathrm{ZnO}$ ternary glass system," Solid State Sciences, vol. 40, pp. 20-30, 2015.

[40] A. Abd El-Moneim, "Correlation between acoustical and structural properties of glasses: Extension of Abd El-Moneim model for bioactive silica based glasses," Materials Chemistry and Physics, vol. 173, pp. 372-378, 2016.

[41] L. A. El Latif, "Ultrasonic study on the role of $\mathrm{Na}_{2} \mathrm{O}$ on the structure of $\mathrm{Na}_{2} \mathrm{O}-\mathrm{B}_{2} \mathrm{O}_{3}$ and $\mathrm{Na}_{2} \mathrm{O}-\mathrm{B}_{2} \mathrm{O}_{3}-\mathrm{SiO}_{2}$ glasses," Journal of Pure and Applied Ultrasonic, vol. 27, no. 2-3, pp. 80-91, 2005.

[42] G. N. Greaves, A. L. Greer, R. S. Lakes, and T. Rouxel, "Poisson's ratio and modern materials," Nature Materials, vol. 10, no. 11, pp. 823-837, 2011.

[43] N. B. Mohamed, A. K. Yahya, M. S. M. Deni, S. N. Mohamed, M. K. Halimah, and H. A. A. Sidek, "Effects of concurrent $\mathrm{TeO}_{2}$ reduction and $\mathrm{ZnO}$ addition on elastic and structural properties of $(90-x) \mathrm{TeO}_{2}-10 \mathrm{Nb}_{2} \mathrm{O}_{5}-(x) \mathrm{ZnO}$ glass," Journal of Non-Crystalline Solids, vol. 356, no. 33-34, pp. 1626-1630, 2010.

[44] B. Bridge, N. D. Patel, and D. N. Waters, "On the elastic constants and structure of the pure inorganic oxide glasses," Physica Status Solidi (A), vol. 77, no. 2, pp. 655-668, 1983.

[45] N. Sasmal, M. Garai, and B. Karmakar, "Influence of Ce, Nd, Sm and Gd oxides on the properties of alkaline-earth borosilicate glass sealant," Journal of Asian Ceramic Societies, vol. 4, no. 1, pp. 29-38, 2016.

[46] T. Rouxel, "Driving force for indentation cracking in glass: composition, pressure and temperature dependence," Philosophical Transactions of the Royal Society A: Mathematical, Physical and Engineering Sciences, vol. 373, no. 2038, Article ID 20140140, 2015.

[47] A. Makishima and J. D. Mackenzie, "Direct calculation of Young's moidulus of glass," Journal of Non-Crystalline Solids, vol. 12, no. 1, pp. 35-45, 1973.
[48] A. Makishima and J. D. Mackenzie, "Calculation of bulk modulus, shear modulus and Poisson's ratio of glass," Journal of Non-Crystalline Solids, vol. 17, no. 2, pp. 147-157, 1975.

[49] J. Rocherulle, C. Ecolivet, M. Poulain, P. Verdier, and Y. Laurent, "Elastic moduli of oxynitride glasses. Extension of Makishima and Mackenzie's theory," Journal of Non-Crystalline Solids, vol. 108, no. 2, pp. 187-193, 1989. 

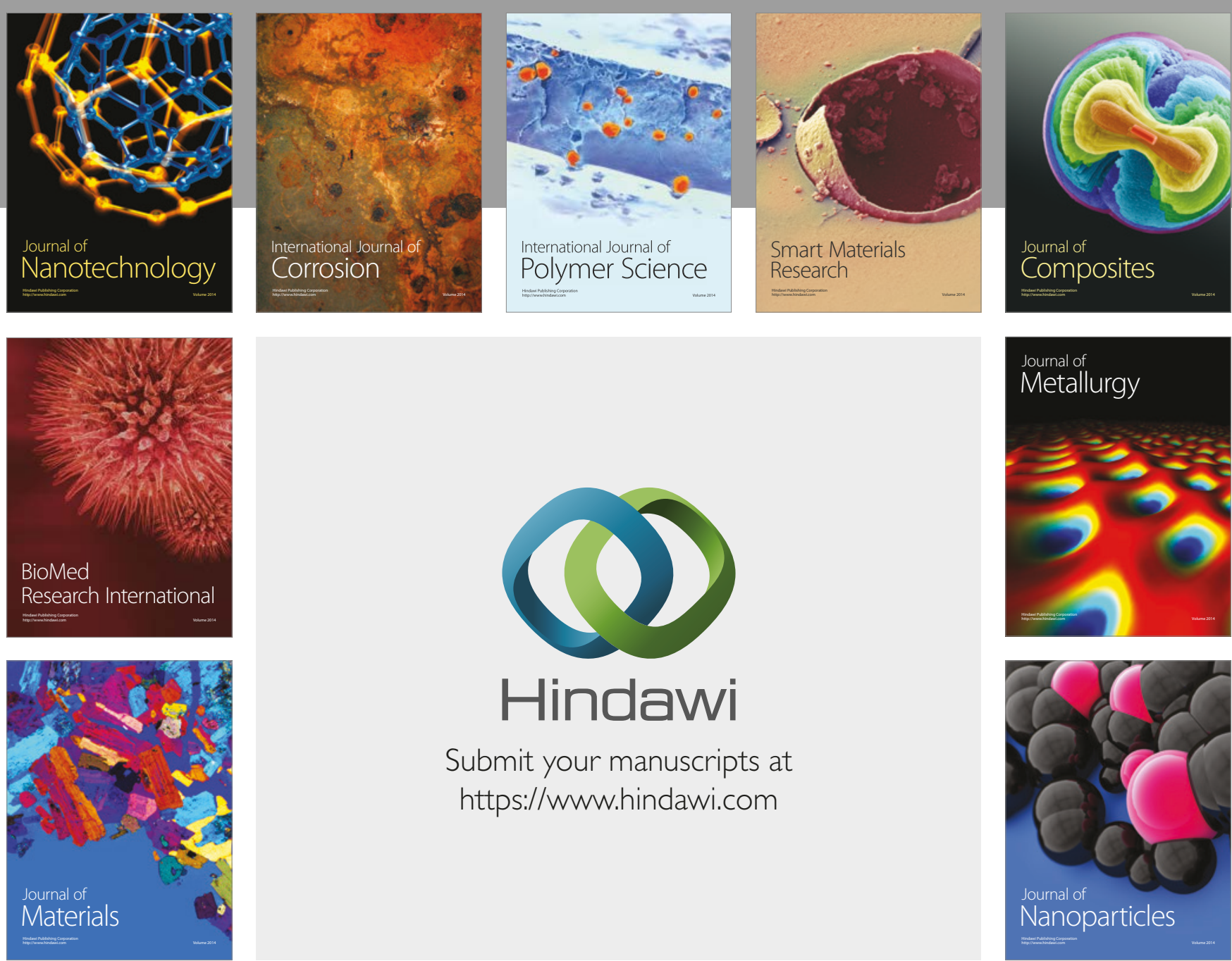

\section{Hindawi}

Submit your manuscripts at

https://www.hindawi.com
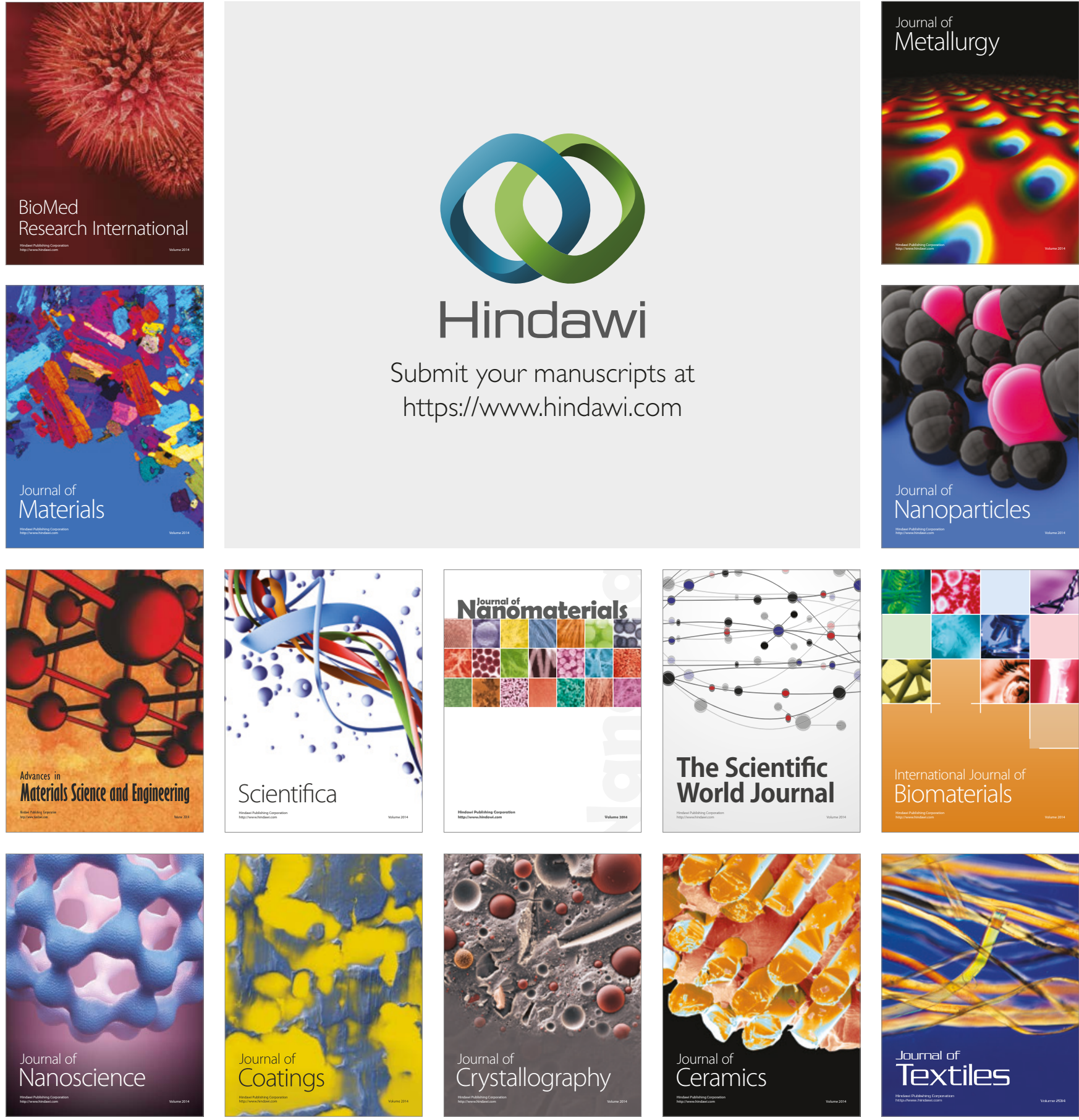

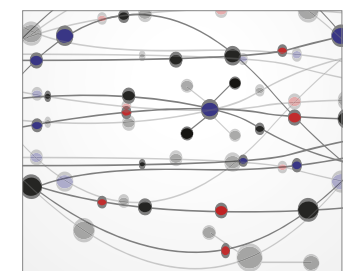

The Scientific World Journal
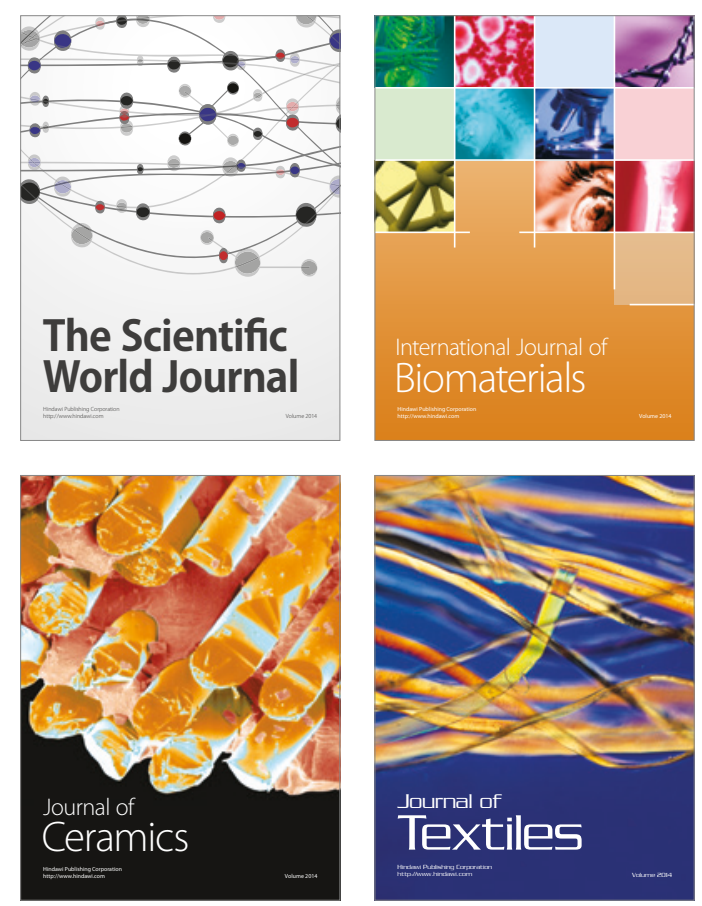